Gut, 1987, 28, 1474-1477

\title{
Influence of olsalazine on gastrointestinal transit in ulcerative colitis
}

\author{
S S C RAO, N W READ, AND C D HOLDSWORTH \\ From the Gastrointestinal Unit, Royal Hallamshire Hospital, Sheffield
}

Summary The effect of olsalazine on stool output and the transit of a solid radiolabelled meal through the stomach, small intestine and colon was studied in six patients with ulcerative colitis intolerant of sulphasalazine. Olsalazine $250 \mathrm{mg}$ four times daily significantly accelerated gastric emptying (mean $\pm \mathrm{SD} ; 45 \cdot 3 \pm 24 \cdot 2 \mathrm{~min} v 67 \cdot 3 \pm 33 \cdot 1 \mathrm{~min}, \mathrm{p}<() \cdot() 5)$, mouth to caecum transit time $(242 \pm 41 \mathrm{~min} v 325 \pm 33 \mathrm{~min}, \mathrm{p}<() \cdot(2)$ and whole gut transit time $(60 \cdot 5 \pm 26 \mathrm{~h} v 37 \cdot 8 \pm 17 \cdot 8 \mathrm{~h}$, $\mathrm{p}<() \cdot() 5)$. No significant changes were seen in mean daily stool weight $(215 \pm 41 \mathrm{~g} v 162 \pm 62 \mathrm{~g})$ and mean daily stool frequency $(2 \cdot 2 \pm() \cdot 6 v 2 \cdot 4 \pm 1 \cdot 8)$. None of these patients developed diarrhoea, but acceleration of gastric and intestinal transit may be responsible for the diarrhoea reported in some patients taking this drug.

Sulphasalazine (SASP) consists of 5-aminosalicylic acid (5-ASA) and sulphapyridine linked together by an azo bond. 5-ASA has now been confirmed as the beneficial moiety of SASP for the treatment of ulcerative colitis.' : Olsalazine is a formulation of 5-ASA and has a similar structure to SASP except that another 5-ASA molecule is substituted for sulphapyridine.; This formulation has now been shown to be effective in the treatment of colitis ${ }^{t 5}$ and is tolerated by $85 \%$ of patients intolerant of SASP." Up to $10 \%$ of patients are reported to have experienced an exacerbation of diarrhoea while taking olsalazine, ${ }^{15}$ however, an adverse effect only rarely seen with SASP.?" In order to study the pathophysiology of the diarrhoea induced by olsalazine, the effect of the drug on stool output and transit of a solid meal through the stomach, small intestine and colon was measured in patients with ulcerative colitis.

Methods

PATIENTS

Paired studies were carried out in six patients with

Address for correspondence: Dr ( 1) Iloldsworth. (iastrointestinal linit J Floor. Royal Hallamshire Hospital. Sheffickd SIO 2.JF. I IK

Received for publication9 April 1987. ulcerative colitis all of whom were intolerant of SASP. The clinical details of the patients and the adverse effects previously experienced with SASP are shown in Table 1 . None of the patients had previously experienced an exacerbation of diarrhoea with SASP. The studies were not placebo controlled as the safety and tolerance of olsalazine was also being investigated and were not randomised as the drug has a long serum half life' and it was thought to be unethical not to prescribe any medication while waiting for the drug to clear from the body. One of the six patients was taking $1.5 \mathrm{~g} /$ day of SASP and one other patient was taking $1.2 \mathrm{~g}$ /day of mesalazine, both of which were discontinued one week before the study. The remaining four patients were on no longterm therapy. The first study served as the

Table 1 ('linical details of patients with ulcerative colitis

\begin{tabular}{|c|c|c|c|c|c|}
\hline "Age & Sex & $\begin{array}{l}\text { Disease } \\
\text { extent }\end{array}$ & $\begin{array}{l}\text { Disease } \\
\text { activity }\end{array}$ & $\begin{array}{l}\text { Adrersereaction to } \\
\text { sulphasalazine }\end{array}$ & $\begin{array}{l}\text { Durationof } \\
\text { disesase (yr) }\end{array}$ \\
\hline 175 & M & Total & Quicscent & Rash & 6 \\
\hline 244 & $F$ & Distial & Ouiciscent & I)yspepsia & 15 \\
\hline 366 & F & Distal & Aclive & Dyspepsia, headache & is \\
\hline $4+2$ & M & Proctitis & Quicscent & $\begin{array}{l}\text { Depression, headache } \\
\text { dyspepsia }\end{array}$ & 1 \\
\hline 570 & $\mathrm{~F}$ & Distal & Ouicscent & Rash & 3 \\
\hline 653 & M & Distal & Ouicscent & Dyspepsia & 3 \\
\hline
\end{tabular}


control and no medication was taken except in the case of patient 3 (Table 1) who was on oral prednisolone sulphate which was continued. After completion of the first study, the patients were prescribed olsalazine (250 $\mathrm{mg}$ capsules), the dose of which was gradually increased over the first week to one capsule four times daily. After four weeks the meal transit study was repeated, giving one capsule with the meal. Sigmoidoscopy and rectal biopsy were done a few days before each study to assess the activity of the disease. A full blood count, ESR, and liver biochemistry were also checked before each study.

The methods used for measuring transit were identical to those described previously." "In brief, the meal consisted of $150 \mathrm{~g}$ mashed potato, $120 \mathrm{~g}$ baked beans, and $50 \mathrm{ml}$ water. ${ }^{*} \mathrm{~m}$ Tc-tin colloid 0.93 $\mathrm{MBq}$ and 50 segments $(2 \mathrm{~mm} \times 3 \mathrm{~mm})$ of radioopaque tubing were incorporated in the mashed potato. All subjects ingested the meal after an overnight fast and gastric emptying was determined from radioactive counts recorded every 10 minutes by means of a single crystal scintillation detector (Type DMI-2, Nuclear Enterprises Ltd) positioned in front of the stomach over the area of maximum radioactivity. The time taken for the radioactive counts to fall to half the initial value $\left(t_{1}\right)$ was taken as an index of gastric emptying. Mouth to caecum transit was determined by measuring the time interval between eating the meal and a sustained rise in breath hydrogen concentration defined as a rise of $3 \mathrm{ppm}$ over three consecutive 10 minute recordings. To record whole gut transit time, subjects were requested to collect the results of each bowel movement in separate polythylene bags for a period of at least 72 hours and label them with the date and time. These were weighed and radiographed to determine the number of markers present. The time taken for the subject to void $50 \%$ of markers provided an index of the whole gut transit.

\section{ETHICAI. CONSIIDERATION}

The protocol for the study was approved on 6 November, 1984, by the Ethical Committee for the Sheffield Health Authority. All patients gave written informed consent for the studies to be carried out.

STATISTICAI. ANAIYYSIS

The significance of the differences in measurements of gastrointestinal transit and stool output, between the first and second studies was determined using Student's paired $t$ test.

\section{Results}

(i ASTRIC EMPTYING; $\left(t_{1_{2}}\right)$

The half time for gastric emptying was significantly accelerated during olsalazine administration (Fig. 1 , Table 2).
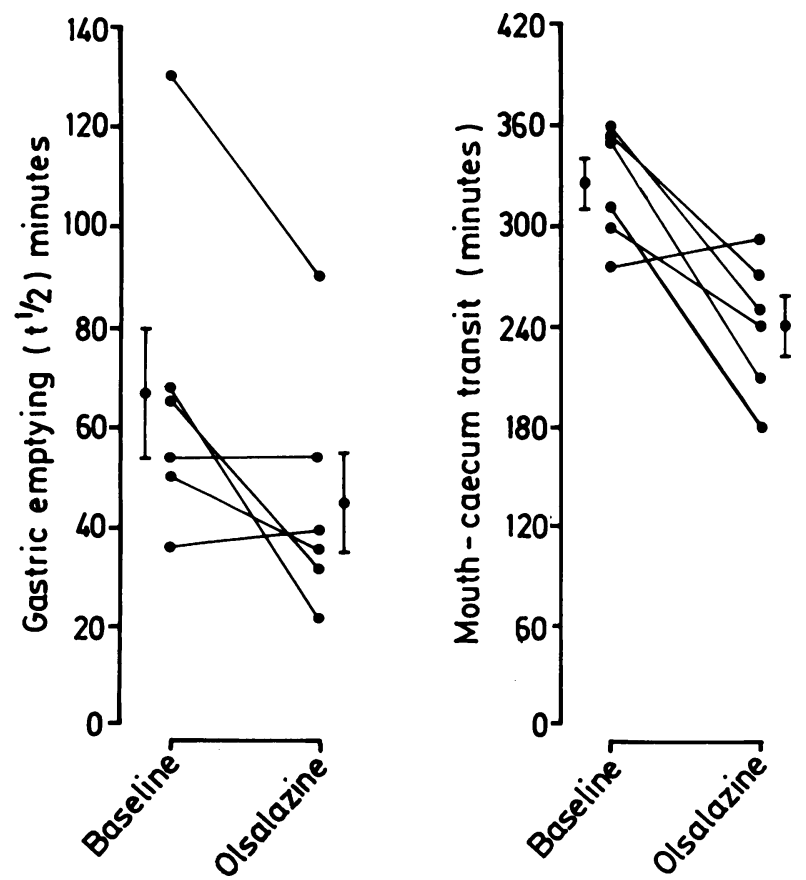

Fig. 1 Effect of olsalazinc on the gastrointestinal transit of a solid meal.

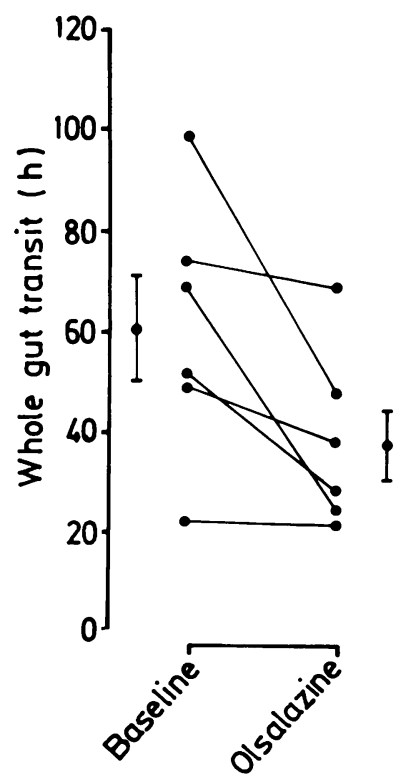


Table 2 Effect of olsalazine on gastrointestinal transit and stool output in patients with ulcerative colitis

\begin{tabular}{|c|c|c|c|}
\hline & Baseline & Olsalazine & $p$ \\
\hline (iastric emptying $t_{2}(\min )$ & $67 \cdot 3 \pm 3.3 \cdot 1$ & $45 \cdot 3 \pm 24 \cdot 2$ & $<(1) \cdot(1)$ \\
\hline Mouth to caccum transit ( $\mathrm{min}$ ) & $325 \pm 33$ & $242 \pm 41$ & $<0 \cdot(1) 2$ \\
\hline Whole gut transit (h) & $60.5 \pm 26$ & $37 \cdot 8 \pm 17 \cdot 8$ & $<(1) \cdot(1)$ \\
\hline Mcian daily stool frequency & $2 \cdot 4 \pm 1 \cdot 8$ & $2 \cdot 2 \pm(1) \cdot 6$ & NS \\
\hline Mcan daily stool weight (g) & $162 \pm 62$ & $215 \pm 76$ & NS \\
\hline
\end{tabular}

Results are expressed as mean \pm SI)

MOUTH TO CAECUM TRANSIT

The mouth to caecum transit time was also significantly faster during ingestion of olsalazine (Fig. 1, Table 2).

WHOLE GUT TRANSIT TIME

The time taken to void $50 \%$ of markers was significantly accelerated during administration of olsalazine (Fig. 1, Table 2).

\section{STOOL OUTPUT}

The daily stool weight was higher during olsalazine treatment in five of the six patients but the increase was not statistically significant (Fig. 2, Table 2). There were no differences in the daily stool frequency between the two periods (Fig. 2, Table 2).

TOLERANCE OF OI.SAI.AZINE

All six patients tolerated olsalazine without any adverse experience. No haematological or biochemical abnormalities were detected during the study. Five patients continued to be in remission at four weeks and the disease activity of patient 3 (Table 1) was unchanged.

\section{Discussion}

The results of this study show that olsalazine accelerated gastric emptying, mouth to caecum transit and whole gut transit time of a solid meal. The accelerated gastric emptying is presumably the result of a direct effect of the drug on gastric motility. The rapid small bowel transit could be either because of a direct action of the drug on small intestinal contractile activity or drug induced hypersecretion or diminished absorption," which could enhance propulsion by distending the lumen and inducing peristalsis. The net effect in either case will be an increased volume of fluid entering the colon from the small intestine. This is consistent with the observation that olsalazine increases ileostomy effluent.'? The normal colon will accommodate an additional load of 2-3 litres of fluid/day without diarrhoea ${ }^{1:}$ but this capacity may be reduced in patients with ulcerative colitis. ${ }^{1+}$ In our study, although the stool weight did increase in five of
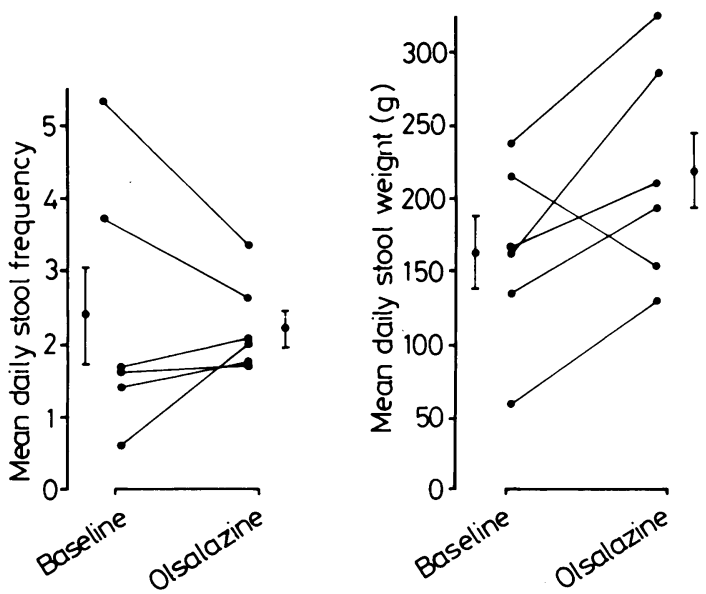

Fig. 2 Effect of olsalazine on stool output. Bars indicate mean $\pm S E M$.

the six patients none of them reported an exacerbation of diarrhoea. This could be because the fact that five patients had distal colitis and only one had total colitis. In a large study, exacerbation of diarrhoea during olsalazine treatment was predominantly seen in patients with total colitis and was unusual in those with distal colitis. Moreover, ingestion of $10(0 \mathrm{ml}$ dilute duphalac (Duphar) containing 20 g lactulose causes diarrhoea in patients with total colitis, but not in patients with distal colitis. ${ }^{15}$ These data suggest that while patients with distal colitis can absorb the increased fluid load from the ileum, induced by olsalazine, patients with total colitis fail to do so and may therefore experience diarrhoea.

A further reason for the low incidence of clinically evident diarrhoea produced by olsalazine is that intestinal transit is usually slow in patients with ulcerative colitis" and olsalazine may reduce transit times to values that are very similar to those seen in normal subjects (mean $\pm S D$, mouth to caecum transit [min] 23() \pm 65 , whole gut transit [h] $48 \cdot 8 \pm$ $22 \cdot 3)$." Indeed in those patients who develop hard stools that are difficult to evacuate, ${ }^{17-21}$ olsalazine could soften the stool.

The authors are grateful to Mrs C Brown and Mrs C Bruce for their technical assistance, to Pharmacia Limited for supply of Olsalazine capsules and to Mrs $J$ Wilson for her secretarial help. Dr Rao is supported by a grant from the Special Trustees for the Former United Sheffield Hospitals.

\section{References}

1 Azad Khan AH. Piris J. Truelove SC. An experiment to determine the active moicty of sulphasalazine. Lancet 1977; ii: $892-95$. 
2 van Hees PAM, Bakker JH. van Tongeren JHM. Effect of sulphapyridine, 5-aminosalicylic acid and placebo in patients with idiopathic proctitis: a study to determine the active therapeutic moiety of sulphasalazine. Gut 1980; $21: 632-5$.

3 Willoughby CP. Aronson JK. Agback H. Bodin NO, Truelove SC. Distribution and metabolism in healthy volunteers of disodium Azodisalicylate, a potential therapeutic agent for ulcerative colitis. Gut 1982: 23: $1081-7$.

4 Selby WS, Barr GD. Ireland A. Mason CH, Jewell DP. Olsalazine in active ulcerative colitis. $\mathrm{Br}$ Med $J$ 1985; 291: $1373-5$.

5 Sandberg-Gertzen H. Jarnerot G, Kraaz W. Azodisal sodium in the treatment of ulcerative colitis. A study of tolerance and relapse-prevention properties. Gastroenterology 1986; 90: 1024-30.

6 Rao SS, Cann PA, Holdsworth CD. Clinical experience of the tolerance of Mesalazine and Olsalazine in patients intolerant of Sulphasalazine. Scand J Gastroenterol 1987; 22: 332-6.

7 Schwartz AG, Targen SR, Saxon A, Weinstein WM. Sulfasalazine induced exacerbation of ulcerative colitis. N Engl J Med 1983; 306: 409-12.

8 Ring FA, Herschfield MB, Machin GA, Scott RB. Sulphasalazine induced colitis complicating idiopathic ulcerative colitis. Can Med Assoc J 1984; 131: 43-5.

9 Read NW, Miles CA. Fisher D, et al. Transit of a meal through the stomach, small intestine and colon in normal subjects and its role in the pathogenesis of diarrhoea. Gastroenterology 1980; 79: 1276-82.

10 Cann PA, Read NW, Brown C, Hobson N, Holdsworth $\mathrm{CD}$. Irritable bowel syndrome: relationship of disorders in the transit of a single solid meal to symptom patterns. Gut 1983; 24: 405-11.
11 Goerg KJ, Wanitschke R, Breiling K. Franke M. The effect of disodium azodisalicylate (DSA) on water and electrolyte transfer of the rat ileum and colon in vivo compared with sulfasalazine (SASP), 5-amino salicylic acid (SA) and Sulfapyridine. (jastroenterology 1984; 86: 1091 .

12 Sandberg-Gertzen H, Jarnerot G, Bukhave K. Lauritsen K. Rask-Madsen J. Effect of azodisal sodium and sulphasalazine on ileostomy output of fluid, PGE, and $\mathrm{PGF}_{2,1}$ in subjects with a permanent ileostomy. (itut 1986; 27: $1306-11$.

13 Debongnic JC. Phillips SF. Capacity of human colon to absorb fluid. (Fastroenterology 1978: 74: 698-7(1)3.

14 Rask-Madsen J. Functional alterations in ulcerative colitis. In: Robinson JWL, ed. Intestinal ion transport. Lancaster: MTP Press, 1976: 381-97.

15 Rao SSC, Read NW. Holdsworth CD. Is a failure of colonic salvage of carbohydrate responsible for diarrhoea in ulcerative colitis? [Abstract]. (jut 1986; 27: A 1257.

16 Rao SSC, Read NW. Holdsworth CD. Gastrointestinal transit and stool output in the pathophysiology of diarrhoea in ulcerative colitis (UC) [Abstract]. Clin Sci 1986; 72: suppl 15: 41 .

17 Lennard-Jones JE, Langman MJS, Jones FA. Faccal stasis in procto colitis. Gut 1962; 3: 301-5.

18 Henderson NP. What is ulcerative colitis? Lancet 1954; i: $159-60$.

19 Lennard-Jones JE, Cooper GW. Newell AC, Wilson CWE, Avery Jones F. Observations on idiopathic procitis. Gut 1962; 3: 201-6.

20 Jalan KN, Walker RJ, Prescott RJ, Butterworth STG, Smith AN. Sircus W. Faecal stasis and diverticular disease in ulcerative colitis. Gut 1970) 11: 688-96. 